Supporting Information

\title{
Tough and Sustainable Graft Block Copolymer Thermoplastics
}

Jiuyang Zhang,,$^{\dagger}$ Tuoqi Li, ${ }^{\dagger}$ Alexander M. Mannion, ${ }^{\dagger}$ Deborah K. Schneiderman, ${ }^{+}$ Marc A. Hillmyer and Frank S. Bates ${ }^{\dagger *}$

${ }^{\dagger}$ Department of Chemical Engineering and Materials Science and Department of Chemistry, University of Minnesota, Minneapolis, Minnesota 55455-0431

\section{Experimental Details:}

\section{Materials}

Hydroxypropyl methylcellulose (HPMC15 and HPMC40) was generously provided by the Dow Chemical Company and dried under vacuum at $65^{\circ} \mathrm{C}$ for two days before use. (HPMC15, $\left(M_{n}=15440 \mathrm{~g} / \mathrm{mol}, \mathrm{D}=1.84\right)$ has a degree of substitution of methoxy groups of $1.9\left(\mathrm{DS}_{\mathrm{MeO}}=1.9\right)$ and a degree of substitution of hydroxypropyl group of $0.23\left(\mathrm{DS}_{\mathrm{HPO}}=0.23\right)$; HPMC40, $\left(M_{n}=39700 \mathrm{~g} / \mathrm{mol} ; \mathrm{Ð}=1.86\right)$ has $\mathrm{DS}_{\mathrm{MeO}}=1.85$ and $\mathrm{DS}_{\mathrm{HPO}}=0.19$. Diphenyl phosphate (DPP) $(99 \%$, Sigma-Aldrich) was purchased and dried under vacuum at room temperature for a minimum of 48 hours prior to use. $\beta$-methyl- $\delta$-valerolactone (MVL) and the linear triblock copolymer, $\operatorname{LML}(26,0.3)$, were synthesized according to a previous report. ${ }^{1}$ Tin(II) 2-ethylhexanoate (Sigma-Aldrich) was distilled under reduced pressure before use. All reagents mentioned were stored in an argon-filled dry box. The toluene was dried by passing the solvent through activated alumina columns before collecting in a flame-dried flask. All other solvents were used as received without further purification. All flasks for polymerization were flame dried before use.

\section{Instrumentation.}

${ }^{1} \mathbf{H}$ NMR spectra were collected from $\mathrm{CDCl}_{3}$ solutions on a Varian INOVA-500 spectrometer operating at $500 \mathrm{MHz}$. Chemical shifts are referenced to the protic solvent S6 peaks at $7.26 \mathrm{ppm}$.

SEC analyses were performed on a Thermo Separation Products (TSP) Spectra Systems AS1000 auto sampler equipped with three $5 \mathrm{~mm}$ Phenomenex Phenogel columns, a Waters 515 pump, and a Waters 2410 differential refractive index detector. The samples were run with THF (Sigma-Aldrich) as the carrier solvent at room temperature. The molar mass reported is referenced to polystyrene standards.

Differential Scanning Calorimetry (DSC) Thermal transitions were determined using a Q1000 differential scanning calorimeter (TA instruments). Samples (5 10 mg) were loaded into hermetically sealed aluminum DSC pans, first heated at a rate of 10 ${ }^{\circ} \mathrm{C} / \mathrm{min}$ to $175{ }^{\circ} \mathrm{C}$ and held for $3 \mathrm{~min}$ to erase any thermal history quenched to $-100{ }^{\circ} \mathrm{C}$, and reheated to $175{ }^{\circ} \mathrm{C}$ at a rate of $10{ }^{\circ} \mathrm{C} / \mathrm{min}$. Glass transition and melting 
temperatures were determined during the second heating run.

Small and Wide Angle X-ray Scattering (SAXS and WAXS) Synchrotron source SAXS measurements were taken at the Advanced Photon Source in Argonne National Laboratory (Argonne, IL) using the beamline at DND-CAT 5-ID-D. SAXS data were recorded with an X-ray energy $17 \mathrm{keV}(\lambda=0.729 \AA)$ and a sample-to-detector distance of $6 \mathrm{~m}$. Samples for SAXS were sealed in hermetical aluminum DSC pans. Samples were first annealed at $170{ }^{\circ} \mathrm{C}$ and then cooled to and stabilized at each temperature for tests. In all cases the patterns were azimuthally isotropic and therefore were reduced to the one-dimensional form as intensity (I) versus scattering wave vector, $q=(4 \pi / \lambda) \sin (\theta / 2)$, where $\theta$ is the scattering angle. The SAXS and WAXS data were taken while cooling from the melt (at $170{ }^{\circ} \mathrm{C}$ ) to a temperature near the PLLA glass transition $\left(50{ }^{\circ} \mathrm{C}\right)$ at a cooling rate of $5{ }^{\circ} \mathrm{C} / \mathrm{min}$. Samples were annealed for 5 minutes at each testing temperature.

Solid Mechanical Property Experiments Samples for mechanical tests were prepared by compression molding the polymer between two Teflon sheets at $175{ }^{\circ} \mathrm{C}$ to form uniform dog-bone shaped specimens (thickness: $\sim 0.5 \mathrm{~mm}$ ) following ASTM standard D1708. Specimens were cooled at a rate of $60 \sim 70{ }^{\circ} \mathrm{C} / \mathrm{min}$ to room temperature and then aged at room temperature for 24 hours under vacuum. Uniaxial tensile tests were performed on a Shimadzu Autograph AGSS17 X Series tensile tester (Columbia, MD) with a cross-head velocity of $5 \mathrm{~mm} / \mathrm{min}$. All tests were conducted according to ASTM standard D1708 and the reported values represent an average over at least five measurements on five identical specimens.

Rheological Experiments A Rheometrics Scientific ARES strain-controlled rheometer with the $25 \mathrm{~mm}$ diameter parallel plate geometry and a forced convection oven with a nitrogen atmosphere was used for the measurements. All polymer samples were loaded to give a gap of approximately $0.5 \mathrm{~mm}$, heated above the melting temperature and annealed before running frequency sweeps. Frequency sweeps were run in the range of $0.01 \leq \omega \leq 100 \mathrm{rad} / \mathrm{s}$. Strains were selected to maximize torque while remaining in the linear viscoelastic regime.

\section{Experimental}

Synthesis of HPMC-g-PMVL polymers. HPMC15- $g$-PMVL and HPMC40- $g$-PMVL were synthesized in a similar way via the utilization of HPMC15 and HPMC40 as macroinitiators, respectively. For example, HPMC15 (220 mg, hydroxyl groups: 1.2 mmol) was charged into a pressure flask and vacuum dried for 12 hours and then the flask was transferred into a glove box. MVL monomer (12.5 g, $0.11 \mathrm{~mol})$ and catalyst (DPP) $(54.8 \mathrm{mg}, 0.22 \mathrm{mmol})$ were added to the flask. The flask was sealed and taken out of the glove box and heated to $80{ }^{\circ} \mathrm{C}$. HPMC15-g-PMVL homopolymers were obtained after 4.5 hours. Samples were taken to determine the monomer conversion. The reaction mixtures were precipitated in diethyl ether to remove unreacted monomers and the polymers were dried in vacuum at $60{ }^{\circ} \mathrm{C}$ for two days. The $M_{n}$ of a single PMVL side-chain was $8.5 \mathrm{~kg} / \mathrm{mol}$, calculated from the conversion based on ${ }^{1} \mathrm{H}$ NMR (peaks at 4.0 and 4.2 ppm from MVL monomer) and end group analysis (peaks 
at $~ 3.7 \mathrm{ppm}$ ). Conversion: $84 \%$, yield: $7.3 \mathrm{~g}, 70 \%$. SEC curve was shown in Figure S2. ${ }^{1} \mathrm{H}$ NMR (Chloroform-D, $\delta$, ppm) (Figure S1); $4.2\left(-\mathrm{CH}_{2} \mathrm{CH}_{2} \mathrm{O}-, 2 \mathrm{H}\right), 2.4$ and 2.2 $\left(-\mathrm{COCH}_{2^{-}}, 2 \mathrm{H}\right), 2.1\left(-\mathrm{CH}_{2} \mathrm{CH}\left(\mathrm{CH}_{3}\right)-, 1 \mathrm{H}\right), 1.7$ and $1.5\left(-\mathrm{CH}_{2} \mathrm{CH}_{2} \mathrm{O}-, 2 \mathrm{H}\right), 1.0$ $\left(-\mathrm{CH}_{2} \mathrm{CH}\left(\mathrm{CH}_{3}\right)-, 3 \mathrm{H}\right)$.

\section{Synthesis of HPMC15-g-(PMVL- $b$-PLLA) and HPMC40-g-(PMVL- $b$-PLLA)} graft block polymers. Several HPMC15-g-(PMVL- $b$-PLLA) and HPMC40-g-(PMVL- $b$-PLLA) graft block copolymers were synthesized using a common synthetic procedure. For example, HPMC15-g-PMVL was used as a macroinitator for HPMC (8.5, 0.7). HPMC15-g-PMVL (2g, hydroxyl groups: 0.24 mmol) was charged into a pressure flask, vacuum dried for 12 hours and then transferred into a glove box. L-lactide monomer $(4.3 \mathrm{~g}, 29.5 \mathrm{mmol})$ and toluene $(15$ $\mathrm{mL})$ and catalyst $\left(\mathrm{Sn}(\mathrm{Oct})_{2}\right)(4.3 \mathrm{mg}, 0.011 \mathrm{mmol})$ were charged into the reaction. The pressure flask was then removed from the glovebox and heated to $80{ }^{\circ} \mathrm{C}$ to dissolve the chemicals and then heated up $105{ }^{\circ} \mathrm{C}$ for 5 hours. Samples were taken to determine conversion and the reaction mixture was then precipitated into methanol to remove unreacted monomers. The polymer was then dried under vacuum and recovered in the form of a white solid. Conversion: $89 \%$, yield: $4.8 \mathrm{~g}, 81 \%$. SEC curve was shown in Figure S2. ${ }^{1} \mathrm{H}$ NMR (Chloroform-D, $\delta$, ppm) (Figure S1 and S3); 5.2 $\left(-\mathrm{COCH}\left(\mathrm{CH}_{3}\right)^{-}, 1 \mathrm{H}\right), 4.2\left(-\mathrm{CH}_{2} \mathrm{CH}_{2} \mathrm{O}-, 2 \mathrm{H}\right), 2.4$ and $2.2\left(-\mathrm{COCH}_{2^{-}}, 2 \mathrm{H}\right), 2.1$ $\left(-\mathrm{CH}_{2} \mathrm{CH}\left(\mathrm{CH}_{3}\right)^{-}, 1 \mathrm{H}\right), 1.6\left(-\mathrm{COCH}\left(\mathrm{CH}_{3}\right)^{-}, 3 \mathrm{H}\right), 1.7$ and $1.5\left(-\mathrm{CH}_{2} \mathrm{CH}_{2} \mathrm{O}-, 2 \mathrm{H}\right), 1.0$ $\left(-\mathrm{CH}_{2} \mathrm{CH}\left(\mathrm{CH}_{3}\right)-, 3 \mathrm{H}\right)$.

Synthesis of HPMC40-g-PLLA polymers. HPMC40- $g$-PLLA was synthesized in bulk using HPMC40 as a macroinitiator. HPMC40 (60.3 mg, hydroxyl groups: 0.33 mmol) was charged into a pressure flask and dried under vacuum for 12 hours. L-lactide $(6 \mathrm{~g}, 41.6 \mathrm{mmol})$ and $6 \mathrm{mg} \mathrm{Sn}(\mathrm{Oct})_{2}(0.015 \mathrm{mmol})$ were added to the flask in a glove box. The pressure flask was then heated to $140{ }^{\circ} \mathrm{C}$. HPMC40 was dissolved immediately by the melted L-lactide. The polymerization was stopped after 1.5 hour and sample was taken to determine the conversion. The reaction mixture was then precipitated into methanol and then dried under vacuum for 24 hours. Conversion: 91\%, yield: $5.1 \mathrm{~g}, 84 \%$. SEC curve was shown in Figure S9. ${ }^{1} \mathrm{H}$ NMR (Chloroform-D, $\delta$, ppm) (not shown): $5.2\left(-\mathrm{COCH}\left(\mathrm{CH}_{3}\right)-, 1 \mathrm{H}\right), 1.6\left(-\mathrm{COCH}\left(\mathrm{CH}_{3}\right)-, 3 \mathrm{H}\right)$.

Calculation of Molecular Weight of HPMC-graft Polymers. Number average molecular weights $\left(M_{\mathrm{n}}\right)$ for the HPMC15 and HPMC40 graft homopolymers and block copolymers were estimated by combining the ratio of the end group to repeat unit concentration of the graft polymer as determined by ${ }^{1} \mathrm{H}$ NMR, which yields $M_{n}$ of the graft chains, and the number of grafted chains per HPMC, assumed to be equal to the number of hydroxyl groups, i.e., one per sugar moiety. For example, HPMC15 $\left(M_{n}=15440 \mathrm{~g} / \mathrm{mol}\right)$ contains approximately 76 hydroxy groups, hence we assume 76 graft blocks in HPMC15 $(8.5,0.5)$. End-group analysis yields $M_{n}=8.5 \mathrm{~kg} / \mathrm{mol}$ and $9.2 \mathrm{~kg} / \mathrm{mol}$ for the PMVL and PLLA blocks, respectively, leading to an estimated overall graft block copolymer molecular weight of $M_{n}=1360 \mathrm{~kg} / \mathrm{mol}$. 


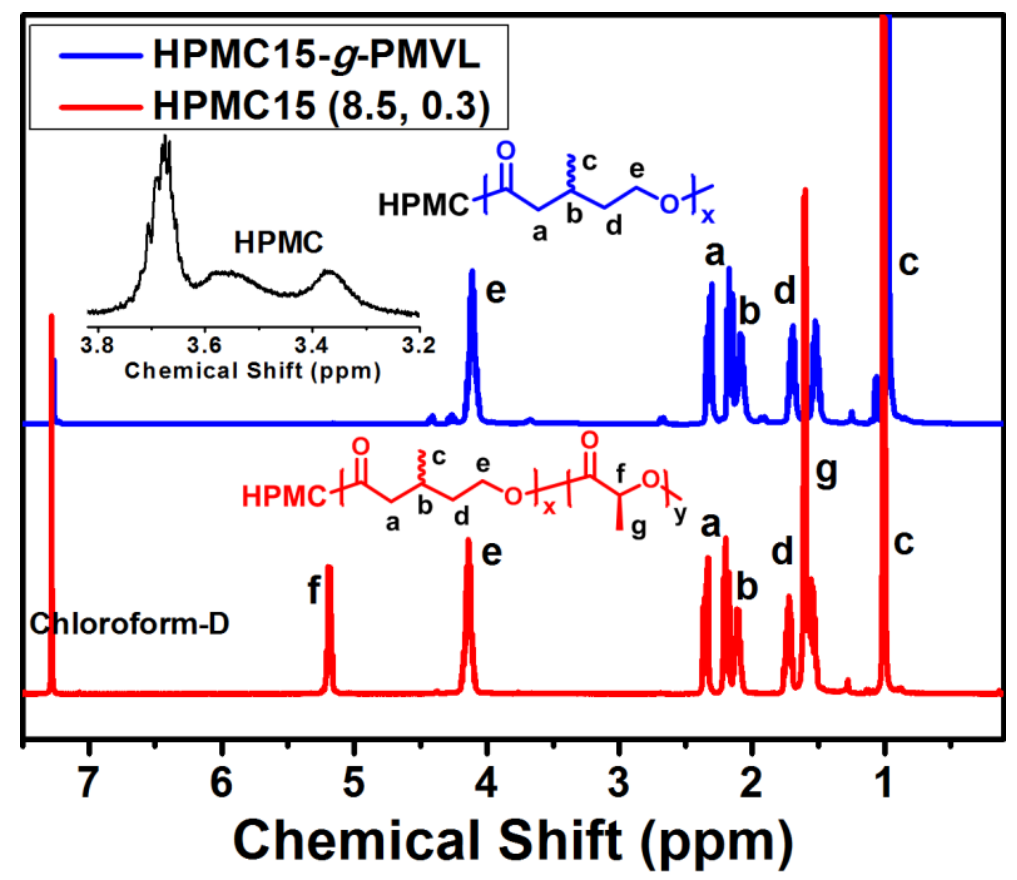

Figure S1. ${ }^{1} \mathrm{H}$ NMR spectra for HPMC-g-PMVL homopolymer and one HPMC15 (8.5, 0.3) graft block polymer. Inserted picture shows the zoomed in area of HPMC-g-PMVL from $3.2 \mathrm{ppm}$ to $3.8 \mathrm{ppm}$ for HPMC and end group of PMVL side-chains (protons nearby end hydroxyl groups).

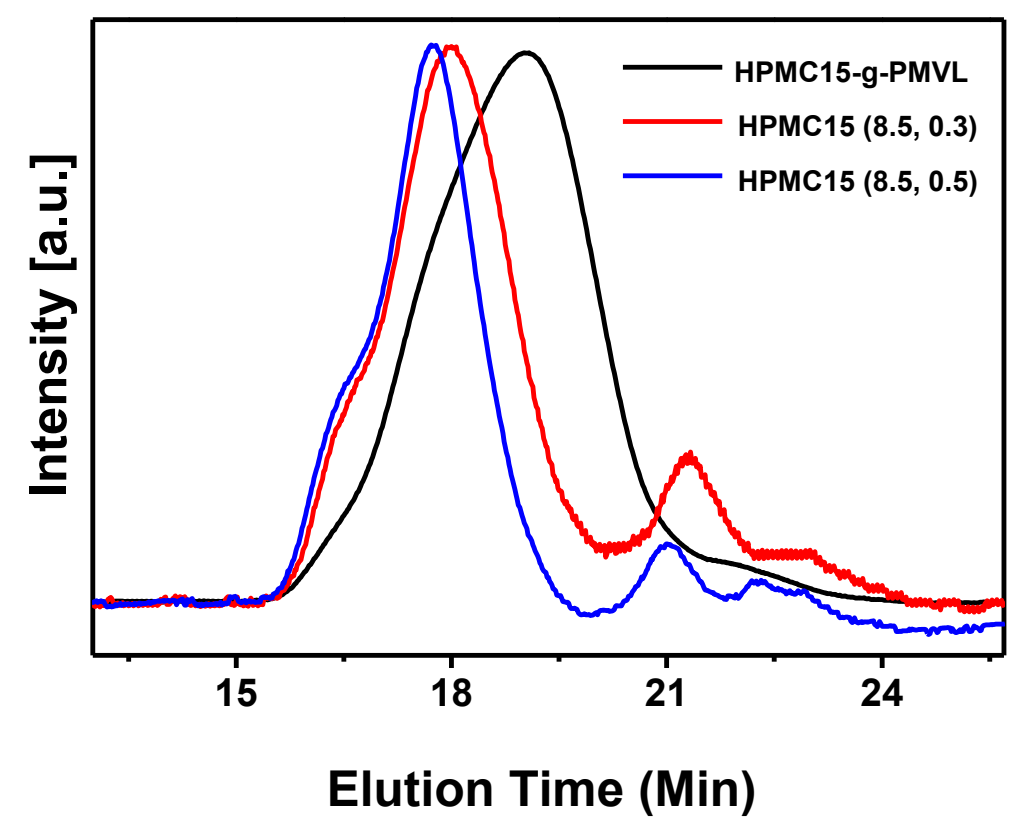

Figure S2. SEC spectra for HPMC15-g-PMVL graft homopolymer and HPMC15-g-(PMVL- $b$-PLLA) graft copolymers. The small peaks at high elution times are most likely PMVL and PMVL- $b$-PLLA resulting from adventitious initiation. 


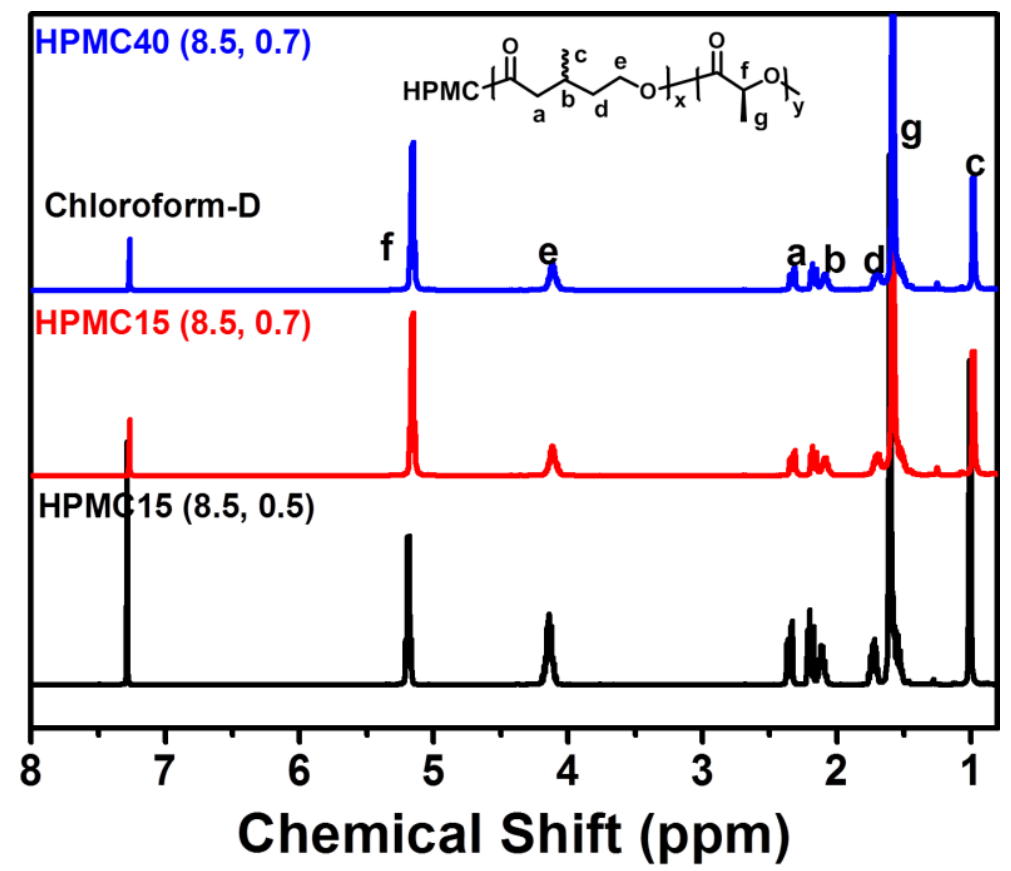

Figure S3. ${ }^{1} \mathrm{H}$ NMR spectra for HPMC15-graft block and HPMC40-graft block copolymers.

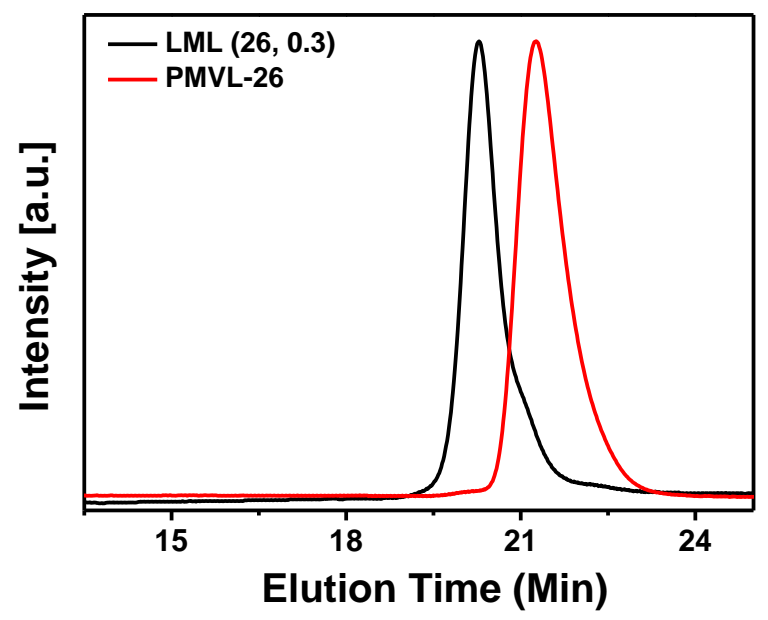

Figure S4. SEC traces for linear PMVL-26 homopolymer $\left(M_{n}=26 \mathrm{kDa}\right.$ based on ${ }^{1} \mathrm{H}$ NMR) and the associated triblock copolymer LML $(26,0.3)$. 


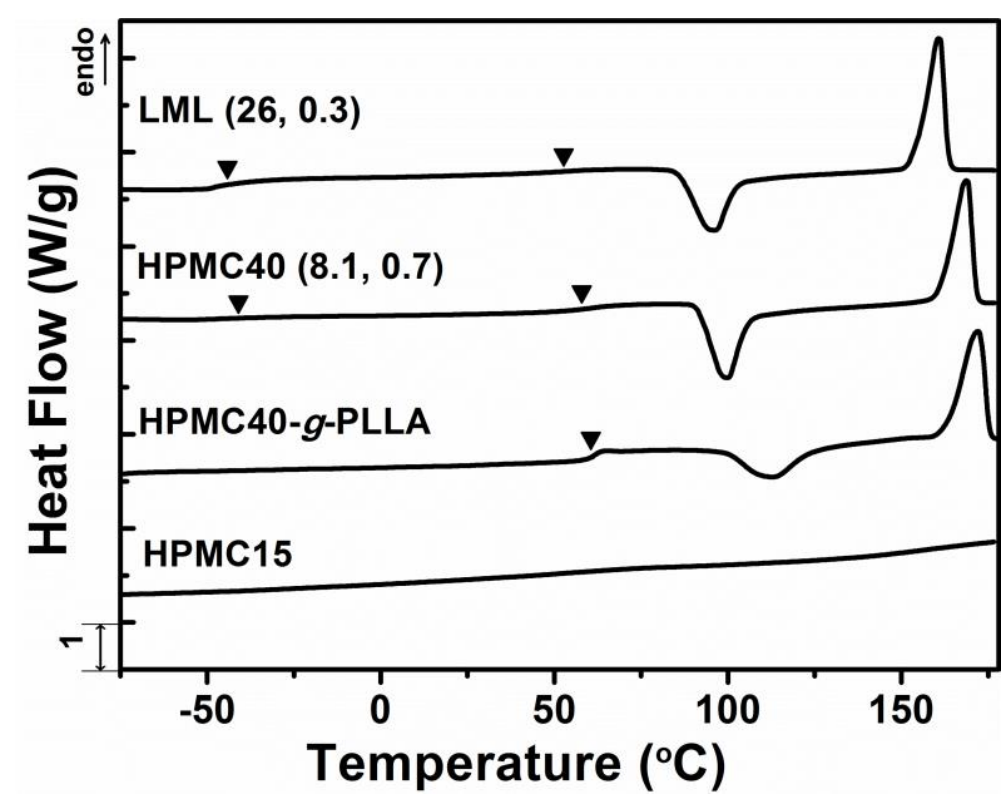

Figure S5. DSC heating curves for HPMC40 $(8.1,0.7)$ graft block copolymer, LML (26, 0.3) linear triblock copolymer, HPMC40-g-PLLA and HPMC15. Arrows indicates $\mathrm{T}_{\mathrm{g}}$ values for PMVL and PLLA ( $\mathrm{T}_{\mathrm{g}, \text { PMVL }}$ and $\left.\mathrm{T}_{\mathrm{g}, \text { PLLA }}\right)$. Data were recorded at a heating rate of $10^{\circ} \mathrm{C} / \mathrm{min}$ following cooling from $175^{\circ} \mathrm{C}$.

Table S1. Tensile properties of HPMC15-graft, HPMC40-graft and linear triblock copolymers.

\begin{tabular}{ccccc}
\hline Samples & $\mathbf{E}(\mathbf{M P a})^{\mathbf{a}}$ & $\boldsymbol{\sigma}_{\mathbf{b}}(\mathbf{M P a})$ & $\varepsilon_{\boldsymbol{b}}(\boldsymbol{\%})$ & $\begin{array}{c}\text { Toughness } \\
\left(\mathbf{M J} / \mathbf{m}^{\mathbf{3}}\right)^{\mathbf{b}}\end{array}$ \\
\hline HPMC15 (8.5, 0.3) & $6 \pm 2$ & $3.7 \pm 0.2$ & $739 \pm 42$ & 26 \\
HPMC15 (8.5, 0.5) & $71 \pm 6$ & $15.7 \pm 0.6$ & $779 \pm 58$ & 89 \\
HPMC15 (8.5, 0.7) & $518 \pm 17$ & $21.6 \pm 1.0$ & $327 \pm 25$ & 64 \\
HPMC40 (8.1, 0.7) & $495 \pm 18$ & $27.2 \pm 2.1$ & $602 \pm 31$ & 129 \\
LML (26, 0.3) & $32 \pm 6$ & $8.0 \pm 0.3$ & $250 \pm 22$ & 17 \\
HPMC40-g-PLLA & $988 \pm 57$ & $48.5 \pm 1.0$ & $6 \pm 1$ & 2 \\
\hline
\end{tabular}

${ }^{a}$ Room temperature Young's modulus (E) determined from the slope of the fitting line to the linear elastic regime of stress-strain curves. ${ }^{\mathbf{b}}$ Tensile toughness determined by integrating the area under stress-strain curves up to the specimen breaking point. 

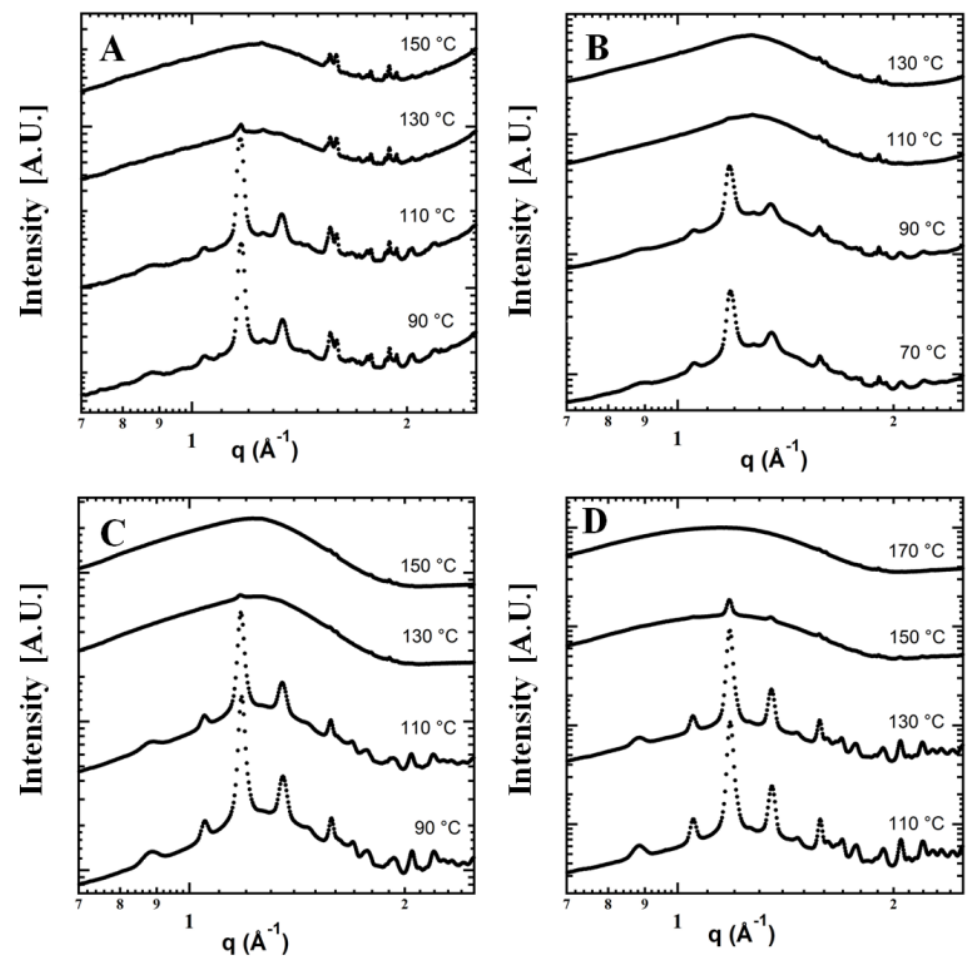

Figure S6. Wide angle x-ray scattering (WAXS) obtained at different temperatures for (A) triblock copolymer (LML (26, 0.3)); (B) HPMC15 (8.5, 0.3); (C) HPMC15 (8.5, $0.5)$ and (D) HPMC15 (8.5, 0.7).
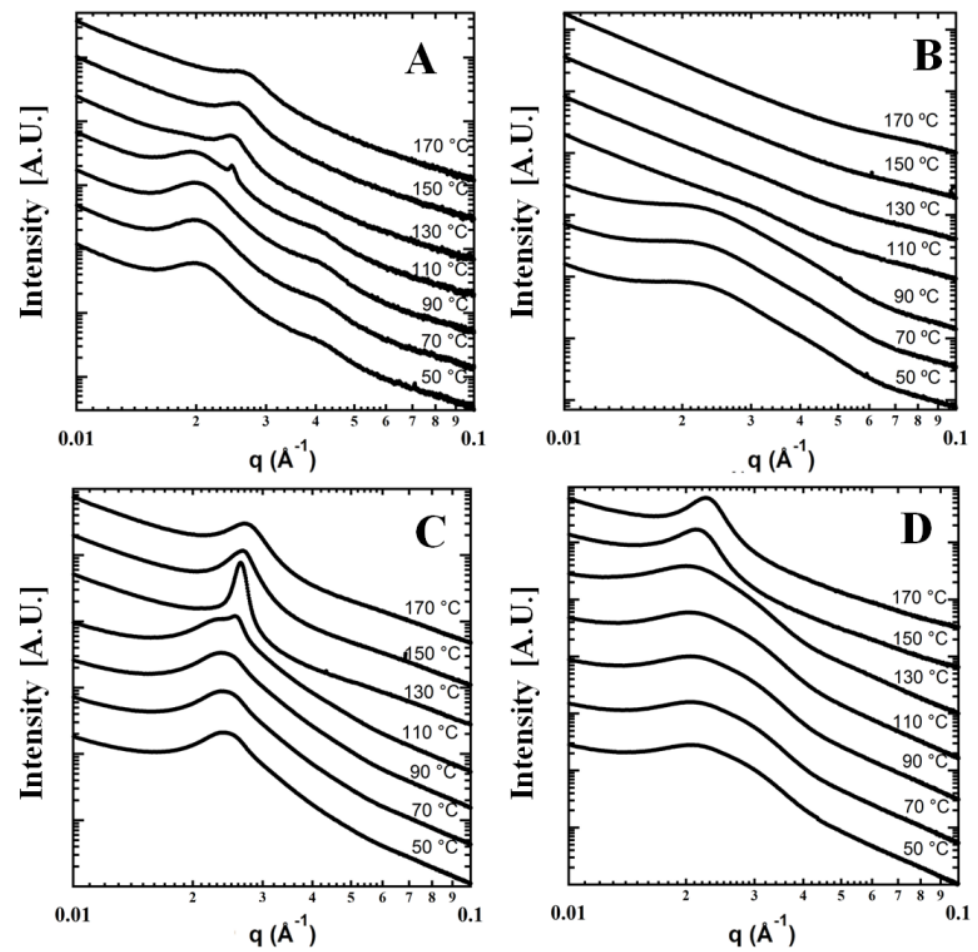

Figure S7. Small angle x-ray scattering (SAXS) obtained at different temperatures for (A) triblock copolymer (LML (26, 0.3)); (B) HPMC15 (8.5, 0.3); (C) HPMC15 (8.5, $0.5)$ and (D) HPMC15 (8.5, 0.7). 


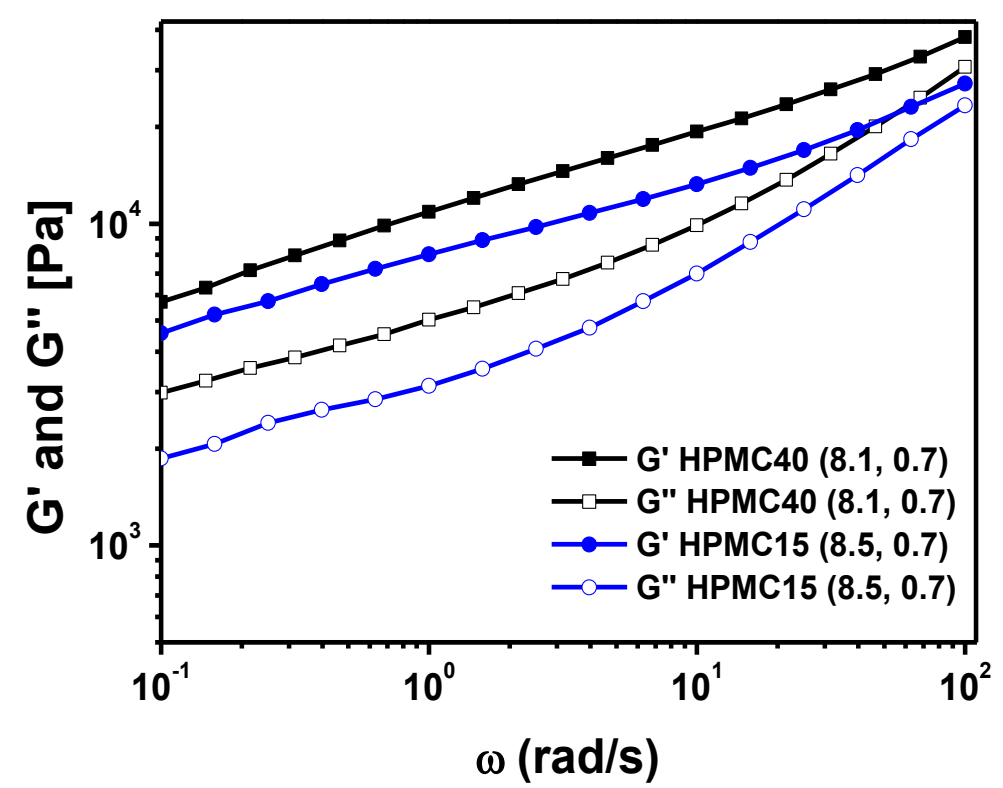

Figure S8. Dynamic mechanical spectroscopy frequency sweep data obtained at $170{ }^{\circ} \mathrm{C}$ with a strain amplitude of $1 \%$ from graft copolymers derived from HPMC15 and HPMC40.

Table S2. Summary of the crystallinity of PLLA blocks in the tensile samples. The first heating trace of DSC has been used for analyses in order to investigate the influences from the sample processing route.

\begin{tabular}{cccc}
\hline Sample & ${ }^{\mathbf{a}} \Delta \mathbf{H}_{\mathrm{c}}(\mathbf{J} / \mathbf{g})$ & ${ }^{\mathbf{b}} \Delta \mathbf{H}_{\mathrm{m}}(\mathbf{J} / \mathbf{g})$ & ${ }^{\mathbf{c}} \Phi_{\text {PLLA }}(\%)$ \\
\hline HPMC15 $(\mathbf{8 . 5}, \mathbf{0 . 3})$ & 7.2 & 9.1 & 6.5 \\
HPMC15 (8.5, 0.5) & 20.7 & 23.6 & 6.1 \\
HPMC15 (8.5, 0.7) & 27.5 & 32.4 & 7.4 \\
HPMC40 (8.5, 0.7) & 26.4 & 31.5 & 7.7 \\
LML (26, 0.3) & 19.9 & 23.8 & 13.5
\end{tabular}

a, b $\overline{\text { The enthalpy of PLLA crystallization and melting were determined by the integrated area of associated }}$ crystallization and melting peaks on the first heating ramp with a rate of $10{ }^{\circ} \mathrm{C} / \mathrm{min}$.

${ }^{\mathrm{c}}$ Crystallinity was calculated using $93.0 \mathrm{~J} / \mathrm{g}$ for theoretical enthalpy of infinite PLLA crystals. ${ }^{2}$ 
Table S3. Additional composition characteristics of HPMC- $g$-PMVL homopolymers and HPMC- $g$-(PMVL- $b$-PLLA) graft copolymers.

\begin{tabular}{|c|c|c|c|c|}
\hline Samples & $\begin{array}{c}{ }^{\mathrm{a}} M_{n} \\
(\mathrm{~kg} / \mathrm{mol})\end{array}$ & $\begin{array}{c}{ }^{\mathrm{a}} M_{w} \\
(\mathrm{~kg} / \mathrm{mol})\end{array}$ & $\begin{array}{l}{ }^{b} w_{L} \\
(\%)\end{array}$ & $\begin{array}{l}{ }^{\mathrm{d}} f_{L} \\
(\%)\end{array}$ \\
\hline HPMC15-g-PMVL & 204 & 379 & & - \\
\hline HPMC15 $(8.5,0.3)$ & 428 & 642 & 33 & 31 \\
\hline HPMC15 $(8.5,0.5)$ & 503 & 805 & 51 & 48 \\
\hline HPMC15 $(8.5,0.7)$ & $-{ }^{c}$ & $-{ }^{c}$ & 70 & 69 \\
\hline HPMC40 $(8.1,0.7)$ & $-^{c}$ & $-^{c}$ & 71 & 70 \\
\hline LML $(26,0.3)$ & 71 & 78 & 31 & 28 \\
\hline $\begin{array}{l}M_{n} \text { and } M_{w} \text { are obtained from } \\
\text { weights of each components. } \\
\text { columns. }{ }^{d} \text { Volume fraction of } \\
\text { densities. }{ }^{1}\end{array}$ & $\begin{array}{l}\text { eight fractic } \\
15(8.5,0.7 \\
\%) \text { calculat }\end{array}$ & $\begin{array}{l}\text { LLA }\left(w_{L} \%\right) \\
\text { dPMC40 ( } 8 \\
\text { d on publis }\end{array}$ & cermir & $\begin{array}{l}\text { NMR } \\
\text { hrough } \\
\text { om ter }\end{array}$ \\
\hline
\end{tabular}

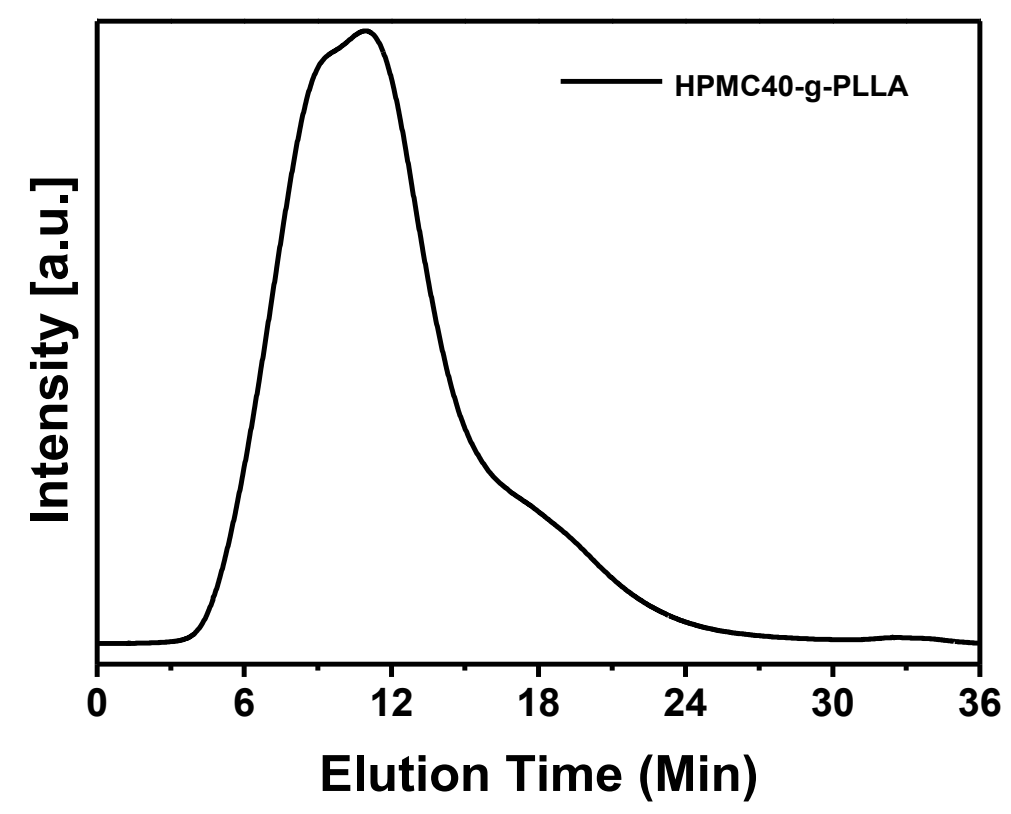

Figure S9. SEC trace for HPMC40-g-PLLA ( $=1.8)$. The grafted PLLA arms have a molecular weight of $17 \mathrm{~kg} / \mathrm{mol}$ based on ${ }^{1} \mathrm{H}$ NMR analysis. 


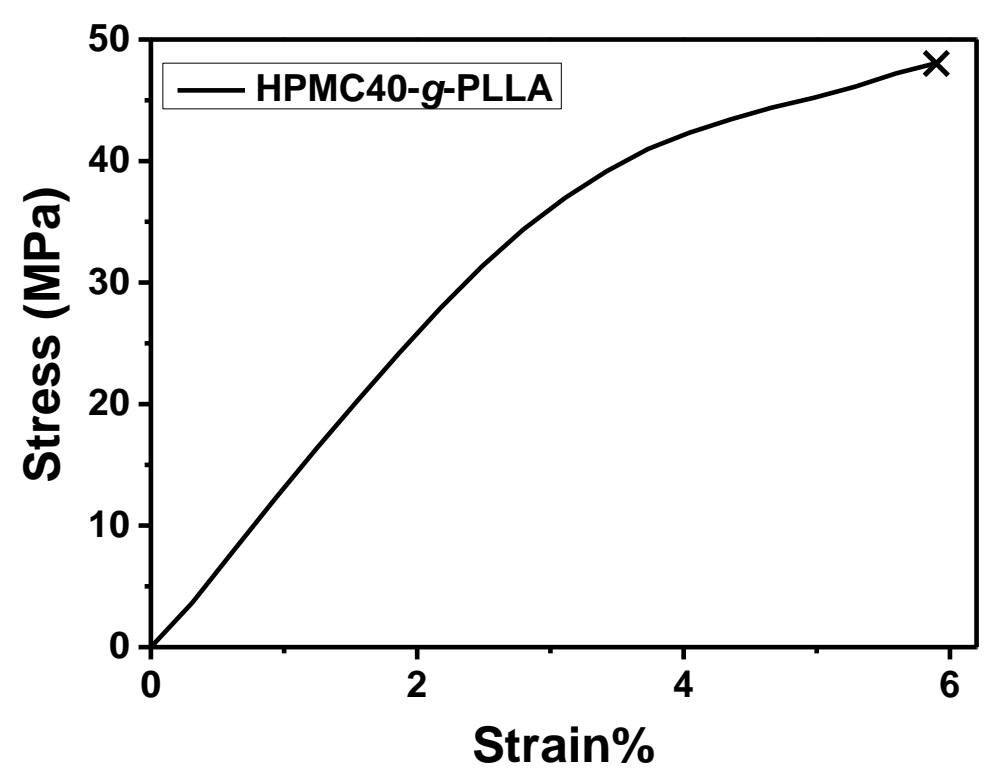

Figure S10. Tensile test of HPMC40-g-PLLA graft homopolymer obtained at room temperature.

\section{Reference}

(1) Xiong, M. Y.; Schneiderman, D. K.; Bates, F. S.; Hillmyer, M. A.; Zhang, K. C. Proc. Natl. Acad. Sci. U.S.A. 2014, 111, 8357-8362.

(2) Panthani, T. R.; Bates, F. S. Macromolecules 2015, 48, 4529-4540. 